\title{
Fontes governamentais de informação para/sobre o trabalho
}

\author{
Governmentals sources of information for/about labor
}

Maria Elizabeth de AZEVEDO'

\section{R E S U M O}

\section{A B S T R A C T}

\begin{abstract}
Nesse estudo contemplamos a informação pública organizada e disseminada pelos governos no campo do trabalho. O texto resgata os conceitos de informação, informação pública, informação governamental e identifica o que pode ser considerado informação para/sobre o trabalho de órgãos nacionais e internacionais. As contribuições da Ciência da Informação mostram-se úteis para auxiliar na importante escolha de um modelo teórico e colocar os desafios da investigação quanto à identificação das fontes, tipologias e das lógicas de organização e disseminação das informações sobre/para o trabalho.
\end{abstract}

Palavras-chave: informação governamental, disseminação da informação, informação para/sobre o trabalho.

This study examines the public information organized and disseminated by governments. The text recovers the concepts of information, governmental information and identifies what could be considered information for and about labor. The international and national labor information services will also be appreciated in this study. Contributions of the Information Science will be helpful to uphold the important selection of a theoretical model and promote research challenges as to the identification of sources, grouping and the information for and about labor organization and dissemination logic.

Key words: public information, dissemination of the information, information for and about labor.

\footnotetext{
${ }^{1}$ Mestre em Ciência da Informação, Docente, Faculdade de Relações Públicas, Centro de Linguagem e Comunicação, Pontifícia Universidade Católica de Campinas. Rod. D. Pedro I, km 136, Parque das Universidades. Campinas, SP, Brasil. E-mail: <meaz@ig.com.br>.

Recebido em 9/9/2005 e aceito para publicação em 17/10/2005.
} 


\section{N T R O D U Ç Ã O}

Este trabalho tem como objetivo dar uma visão sobre um tipo especial de informação que é relativa ao tema trabalho. São apresentadas as principais fontes governamentais de informação para e sobre o trabalho do Brasil e do exterior; os tipos de informação disponibilizadas na Internet; parcerias firmadas para fornecer um elenco de produtos e serviços informacionais; dinâmicas de apresentação das informações nos sites dessas instituições; além das categorias de informações que aportam.

A informação para/sobre o Trabalho é entendida nesse artigo como insumo para o desenvolvimento e implementação das políticas públicas para o trabalho, dos governos, Federal e Estaduais. A partir do correto delineamento de cenários é que são formuladas as estratégias governamentais e empresariais, são definidos objetivos e metas, são elaborados planos e programas e, conseqüentemente, as chances de uma decisão mais adequada são ampliadas. Para o cidadão, este tipo de informação é útil para que possa orientar-se e desenvolver potencialidades individuais para o mundo do trabalho e para a vida. Na iniciativa privada, os empregadores utilizam as informações disponibilizadas pelos órgãos governamentais para embasar seu planejamento, fazer projeções salariais, estudos de cargos relativos às ocupações, conhecer as tendências gerais no mundo do trabalho, identificar futuros empregados se informarem de suas obrigações com os diversos órgãos governamentais. Portanto são os usuários desse tipo especial de informação, tanto governo, empresas como cidadãos.

Recuperamos para este trabalho, os relacionamentos do Governo Brasileiro previstos pela sociedade da informação (G2G, G2B, G2C) conforme Takahashi (2000), codificação utilizada correspondente aos principais usuários da informação para/sobre o trabalho, sendo G - governo; B - business/instituições externas; e C - cidadão.
O primeiro relacionamento, G2G (Governo

$x$ Governo) corresponde ao fornecimento de dados e informações, desenvolvimento de políticas e programas do governo federal (relacionamento horizontal) e compartilhamento de informações de forma coordenada com os governos estaduais e estes com os municípios (vertical). Os melhores exemplos são os serviços informacionais das Secretarias de Estado, que intermediam e fornecem informações; um órgão que torna-se cliente e fornecedor de outra (Exemplo: IBGE, SINE, Projeto Interlegis do Senado Federal).

O segundo relacionamento, G2B e B2G (Governo x Instituições Externas/Negócios), corresponde às ações do governo que envolvem interações com entidades externas. Como a condução de compras, contratações, licitações etc. via Internet (por exemplo: o controle fiscal e o controle de obrigações sociais sobre as empresas). Hoje o empresariado utiliza a infra-estrutura oferecida e administrada pelo governo para viabilizar seus negócios como por exemplo a intermediação da mão de obra on-line.

O terceiro tipo previsto, G2C e C2G (Governo x Cidadão) corresponde à ação do governo de prestação (ou recebimento) de informações e serviços ao cidadão via meios eletrônicos. Alguns serviços foram organizados e já estão em funcionamento como: disponibilização de informações em websites e em portais; disseminação seletiva de informações; acesso a serviços para o cidadão (quiosques eletrônicos de acesso público); centro de acesso comunitário à Internet e fornecimento de um endereço eletrônico. São exemplos deste tipo: "Poupa Tempo" do Governo do Estado de São Paulo, os Balcões do SINE, etc.

Os relacionamentos $\mathrm{G} 2 \mathrm{C}$ e C2G são os mais complexos devido as diversas assimetrias e oportunidades que impactam a universalização dos serviços de informações governamentais. Tais assimetrias estão ligadas a aspectos culturais que provocam assistência ao aprendizado 
das novas tecnologias, sociais baixo nível de escolaridade, físicos como é o caso do alto custo das ligações telefônicas nas localidades onde não há provedores de acesso locais e econômicos, a baixa renda per capita impossibilita a compra dos computadores.

A organização da informação para e sobre o trabalho na Internet requer uma boa base tecnológica como aquela prevista pelas políticas de comunicação e pela sociedade da informação no Brasil para atingir o maior número de cidadãos e com serviços de boa qualidade. Fazem uso desta base tecnológica órgãos públicos particulares e governamentais. Foram elencadas as principais fontes e serviços informacionais disponíveis no Brasil e no exterior, mediante um trabalho de pesquisa inicial a sites governamentais. O critério utilizado foi o da especialidade, isto é, o site deveria ter como objetivo oferecer serviços de informação para e sobre $o$ trabalho e pertencer a uma instituição governamental ou pública. A partir deste levantamento foi possível identificar as melhores fontes, os tipos de informação que são veiculadas através de registro em mapa construído com os termos palavras e expressões utilizadas e quais as dinâmicas que facilitam a navegação, interação ou o processo de busca e tornam mais atraentes os sites que as suportam. Portanto, identificamos os elementos que deverão ser priorizados em um Serviço de Informação com as características próprias de um serviço gerado e gerenciado no âmbito governamental.

\section{Política de comunicação e políticas nacionais de informação}

$\mathrm{Na}$ competição global, as telecomunicações são recursos estratégicos e conforme Dupas (apud MIOTTO, 2004, p.99) "a manutenção da Internet como veículo público de socialização das informações irá depender de como sua regulação será feita pela sociedade". O mundo encontra-se conectado, com mensagens circulando de um local a outro. "Por isso, a informação converteu-se em componente indispensável da reprodução econômica e dos ganhos de competitividade".

O acesso e o direito à informação tornamse requisito para o exercício da cidadania. Isso exige a produção, organização e disseminação de informações em um rigoroso processo de qualidade, com transparência e fidedignidade. Os veículos de comunicação de massa, potencialmente a Internet, podem colaborar para o fortalecimento da sociedade civil no Brasil, que institui novas formas de ação, reivindicando novas práticas por parte da sociedade política. A Internet pode ser um dos veículos que contribuirá para a institucionalização de mecanismos legais e efetivos no atendimento das demandas sociais, ou seja na construção da cidadania, funcionando como meio de comunicação e de controle.

Embora organismos internacionais (Organização Internacional do Trabalho (OIT) e a Organização dos Estados Americanos (OEA)) e o governo de alguns países já se manifestassem sobre a importância da existência de sistemas amplos de informações, principalmente naqueles de tradição democrática, os meios de transportes da informação existentes não eram suficientes e não atendiam plenamente as necessidades de suas populações. Assim, novos desafios aparecem para os governos no campo das comunicações: de ordem econômica, de desenvolvimento e domínio das tecnologias, de convergências de sistemas e muitos outros.

A possibilidade de entrada do país na competição internacional exigiu dentre outras providências, o desenvolvimento do setor de comunicações e telefonia acessível para a maior parte dos cidadãos. Esta questão causa controvérsia, porém o fato é que a tecnologia (potencialmente acessível a todos) é relevante para o desenvolvimento, pois possibilita a universalização de acesso à informação e ao conhecimento.

A Pesquisa Nacional de Amostra por Domicílio (PNAD) 2003, pesquisa realizada pelo Instituto Brasileiro de Geografia e Estatística 
(IBGE), nos domicílios, aponta que entre os bens duráveis, o computador foi o que mais cresceu nos últimos anos. De 2001 a 2002, o crescimento foi de $15,1 \%$ e de 2002 a 2003 , de $11,4 \%$, sendo que dentre os domicílios que tinham acesso à Internet, o aumento nos dois períodos foi, respectivamente, de $23,5 \%$ e $14 \%$. Em 2003, $15,3 \%$ e em $11,4 \%$, este equipamento tinha acesso à Internet (www.ibge.gov.br). É um crescimento considerável, e que mostra o potencial desse recurso do ponto de vista mercadológico e social.

Além da infra-estrutura, outros desafios se apresentam nesta área: complexos problemas de acesso, falta de habilidades para o uso destas tecnologias, desenvolvimento de conteúdos, entre outros.

Mas, o governo sozinho não implementará nem manterá o processo de mudança, pois "a ação [...] é uma atividade que só pode ser exercida com outros homens e corresponde a condição humana de pluralidade, uma condição de vida política do homem na terra". (BARRETO, 2004, p.1). E para que estes desafios sejam minimizados criou-se em um conjunto de esforços, o movimento sociedade da informação no Brasil.

As aspirações do governo quanto a universalização vão se concretizando com todas as assimetrias apresentadas num país em desenvolvimento, mas ainda há muito o que avançar. O governo brasileiro para concretizar a Sociedade da Informação no Brasil tem vários desafios pela frente. Da época do seu discurso até este momento, muitas ações ainda precisam ser intensificadas e segundo Ferreira (2003, p.1), "esses desafios são representados pelo analfabetismo, pela necessidade de capacitação dos recursos humanos da burocracia do Estado e pela dificuldade do cidadão comum ao acesso às tecnologias da informação".

Se for apenas um situação transitória, "Ritos de Passagem", expressão de Barreto
(2004) outros fatores deverão ser levados em consideração,

Contudo, é um erro pensar que a democratização da informática irá levar à completa Democratização da informação. A primeira forma representa apenas a contribuição para a segunda, a qual constitui um processo mais amplo e que envolve não apenas os conteúdos informacionais disponíveis na Internet, mas toda informação produzida na sociedade, registrada nos mais diferentes suportes e de interesse público [...] (FERREIRA, 2003, p.5).

Para Ferreira (2003, p.5), neste caso, cabe ao Estado discutir junto à sociedade civil $e$ atores econômicos, ações capazes de coibir a veiculação de informações de qualidade duvidosa "que ferem os conteúdos humanos e éticos sobre os quais a democratização da informação deve fundamentar-se".

Barreto (2004) sintetiza o papel do Estado ao afirmar que o destino final de uma política nacional de informação é controlar a geração, e a organização das atividades de informação, visando uma distribuição socialmente justa desta informação, com a intenção de gerar conhecimento no indivíduo e induzir seu desenvolvimento pessoal e seus espaços de convivência.

Senado Federal, Ministério do Trabalho, Ministério do Planejamento e Gestão, Universidades e Secretarias de Estado são exemplos de instituições que estão inseridas no que se convencionou chamar de Governo Eletrônico. Embora ainda não estruturados totalmente, mas na prática já estão em funcionamento os serviços de informação para e sobre o trabalho pelas quais são responsáveis.

A importância dos investimentos em Tecnologia de Informação não criam mais vantagem ou produtividade por si próprios que o investimento em novo maquinário, conforme McGee e Prusak (1994). Para os autores "não é 
a tecnologia, mas sim o seu uso, que cria valor adicional. O valor da tecnologia da informação e do papel desempenhado por ela nas organizações". Assim caberá aos governos como instituição, cujos objetivos estão fora deles, servir aos usuários seus serviços, cuidar da própria tecnologia e de seus usos, afim de que possam devolver o melhor para a sociedade: a informação de qualidade.

Conhecida a política de informação do governo e os modelos de relações previstos em sua política, ou seja G2B, B2G e G2C, estudaremos, na seqüência, as instituições envolvidas no tema de nosso estudo. Aproveitando a base tecnológica disponibilizada pelos governos estaduais e federais aos cidadãos, empresários e aos órgãos do próprio governo as Informações para/sobre o Trabalho, os tipos de informações que estão disponibilizadas para atender a estes segmentos de usuários, as principais fontes de informações e em que formatos as informações são apresentadas.

\section{Conceitos de Fontes de Informação}

Os órgãos governamentais, como toda organização, trabalham com dados e informações. Utilizaremos aqui os conceitos de dado e informação de O'Brien (2003, p.23), para quem dados 'são fatos ou observações crus, normalmente sobre fenômenos físicos', isto é não são elaborados, e considera informação 'como dados que foram convertidos em um contexto significativo e útil para os usuários finais específicos'.

Estes dados e informações disponibilizados para os usuários são produzidos nos próprios órgãos ou adquiridos de fontes externas, passam por um processo de organização e tratamento e uma adequação aos objetivos finais do serviço informacional os quais incluem a satisfação de uma necessidade de indivíduos ou grupos.

Barreto (1999b, p.1), analisa a eficiência econômica e a viabilidade dos produtos e serviços de informação, utilizando o conceito de informação como sendo "conjuntos significantes com a competência e a intenção de gerar conhecimento no indivíduo, em seu grupo, ou na sociedade", ficando a informação qualificada como "um instrumento modificador da consciência do homem e de seu grupo social" e conhecimento como "um processo, um fluxo de informação que se potencializa”. Para ele, a relação entre informação e conhecimento e as práticas necessárias para se trabalhar com a informação enquanto estruturas significantes, precisa ser direcionada para um fim específico. "E, por conseguinte, devemos produzir, organizar, controlar e distribuir a informação de uma maneira correta política e socialmente".

Porém, "os estoques estáticos (grifos do autor) de informação são indispensáveis ao processo de comunicação e geração de conhecimento, mas por si só não efetivam este processo", conforme Barreto. Na organização das informações a serem disponibilizadas, o que se tem em vista é promover o desenvolvimento do indivíduo, de seu grupo e da sociedade e, portanto este é o objetivo de uma Unidade de Transferência de Conhecimento (UTC), que têm como funções básicas: "1) a função de conhecer e fornecer estratégias para disponibilizar estoques de informações; 2) a função de comunicação da informação para promover o conhecimento e desenvolvimento." (BARRETO, 1999b, p.2).

Consideram-se neste estudo, como sítios e portais, não apenas Unidades de Transferência de Conhecimento, mas também Unidades Produtoras e Organizadoras de Conhecimento, enquanto representam para os usuários, as instituições por quem são mantidos.

As fontes de informação para/sobre o trabalho para o presente estudo foram escolhidas entre sítios e portais governamentais da Internet que contemplassem: o maior volume e variedade de informações para/sobre o trabalho; qualidade do texto; dinâmica do conteúdo; possibilidades de interfaces; veicular exclusivamente material 
referente ao campo de estudo. Também foram considerados sítios as instituições privadas que prestam serviço, de caráter público.

Consideramos como fonte de informação qualquer tipo de meio utilizado para obter informações, como centros de informações, softwares, imprensa, entre outras. Campello e Campos (1993, p.17) classificam as fontes de informação em primárias, secundárias e terciárias das quais: "Fontes primárias são aquelas que contém informações originais, ou pelo menos, novas interpretações de fatos e idéias já conhecidas [...]. Fontes secundárias apresentam a informação filtrada e organizada de acordo com um arranjo definido, dependendo da finalidade da obra [...]. Fontes terciárias são aquelas que têm a função de guiar o usuário da informação para as fontes primárias e secundárias [...]."

Os sítios de Internet visitados apresentam características diferentes, como linguagem, programações e softwares distintos, ou combinações de todos eles, que estabelecem diferentes relações com os usuários da rede. Parecem adotar, contudo, a mesma metodologia de organização da informação dos meios impressos. Para Moura (2002, p.27), sobrevivem as adaptações que forem mais bem aceitas pelos usuários. Elas é que serão copiadas, adaptadas e reaplicadas por outros segmentos na rede. "Se o usuário não gosta do sítio, ele não é visitado, é esquecido. Se é esquecido, não se estabelece como um padrão de funcionamento".

Isto acontece porque no hipertexto o acesso é seletivo, conforme Dias (1999, p.1):

O hipertexto se insere no contexto da cibercultura, com uma de suas novas interfaces de comunicação. $\mathrm{Na}$ verdade, o hipertexto resgata e modifica antigas interfaces da escrita [...], implementadas com novas tecnologias. Essa nova maneira de escrever pode ser usada para organizar e dividir o conhecimento sobre uma determinada área do saber, sendo especialmente útil nas áreas de gestão de informação, comunicação e educação.
Levar a informação de modo organizado e atraente são pré-requisitos para que o sítio seja visitado. Se na Internet é o usuário que estabelece sua continuidade, a informação terá que ter credibilidade, atualidade, relevância. Portanto, o gerenciamento de um sítio da Internet, terá que ter como base, um criterioso serviço documental que o sustente.

Um portal deve permitir consultas rápidas e atender a muitos segmentos. Ele antecede e antecipa as novidades que o internauta busca na rede. Na rede trabalha-se com a intuição do internauta, então não se coloca todo o conteúdo numa página de forma desordenada e desestruturada. O hipertexto de acordo com Moura (2002, p.38) "é apenas o texto lincável e dinâmico, funcional num website competente."

Dessa forma, para que os sítios e portais governamentais que disponibilizam informações sobre/para o trabalho atinjam seus objetivos, é preciso que adotem metodologias para a organização do conhecimento (como sistemas de classificação, tesauros, taxonomias corporativas, etc.) e otimizem seus sítios de acordo com as finalidades de seus serviços e perfil de usuários.

Pois, como afirma Lévy (2000, p.25), a estrutura do hipertexto não dá conta somente da comunicação, mas também de processos sociotécnicos. Para ele "O hipertexto é talvez uma metáfora válida para todas as esferas da realidade em que significações estejam em jogo" e caracteriza-se através de seis princípios abstratos que resumimos: princípio da metamorfose (a rede hipertextual está em constante construção e renegociação); princípio da heterogeneidade (associações entre diferentes elementos, como imagens, sons, palavras, sensações, modelos); princípio de multiplicidade e de encaixe das escalas (se organiza em um modo "fractal"); princípio de exterioridade (não possui unidade orgânica, nem motor interno); princípio de topologia (a rede não está no 
espaço, ela é o espaço); princípio de mobilidade de centros (possui permanentemente diversos centros, perpetuamente móveis).

Na pesquisa, procurou-se identificar no hipertexto os termos mais utilizados nos sítios, obedecendo as definições de Lara (2004, p.9): [...] "o termo é uma designação que corresponde a um conceito em uma linguagem de especialidade", para conhecer o que as diversas organizações governamentais estão considerando como informações para/sobre o trabalho.

Foram consultados sítios e portais das instituições (Quadro 1), os quais se constituem em fontes de informação para/sobre o trabalho, conforme os critérios apresentados por Campelo e Campos (1993); Barreto (1999a) e Lara (2004).
As fontes internacionais foram úteis para nos auxiliar na compreensão do que poderia ser considerado informação para/sobre o trabalho, no mundo, porém enfatizamos e tratamos especialmente das fontes nacionais (Quadro 2).

\section{As fontes das fontes de informação para/sobre o trabalho}

As instituições elencadas nos Quadros 1 e 2, oferecem informações produzidas por elas próprias, podendo acrescentar informações de outras fontes que se originam no próprio governo ou buscar parcerias com outras instituições para ampliar seus estoques.

Davenport (1998, p.268) afirma que "nenhuma empresa é uma ilha: todas precisam

Quadro 1. Fontes de Informação para/sobre o Trabalho no Exterior.

Agencia Europea para la Seguridad Y la Salud en el Trabajo - España <http://www.europe.osha.eu.int>

Australian Government - Department of Employment and Workplace Relations - Australian Workplace <http// www.workplace.gov.au>

Bolsa de Trabajo - Guía de Sítios - España <http://varelaenred.com.ar>

CEDIAS - Musée Social - France <http://cedias.org./dossiers/dossiers.php.?id_dossier=87>

Centre de Documentation sur la Formation et le Travail - France <http://www.cnam.fr/doc>

Department of Labour - New Zeland <http://dol.govt.nz>

Direção Geral de Estudos, Estatísticas e Planejamento (DGEEP) - Portugal <www.deep.msst.gob.pt/estatística>

Eures - Portal Europeu da Mobilidade Profissional <http://europa.eu.int/eures/main>

Government du Canada - Human Resources and Skills Development Canadá/Ressources Humaines et Développement des Compétences - Canada <http://www23.hrdc.gc.ca/2001/f.groups/index.shtml>

International Labour Organization (ILO) - Genebra/Library and Information Services <http://www.ilo.org>

Ministère de L'Emploi, du Travail et de la Cohésion Sociale - France <http://www.travail.gouv.fr>

Ministero del Lavoro e delle Politiche Sociali - Itália <http://quadri.welfare.gov.it/quadri/home.asp>

Ministério das Actividades Econômicas e do Trabalho - Portugal <http:www.bi.mct.pt>

Ministerio de Trabajo, Empleo, Seguridad Social - Argentina <http//www.trabajo.gov.ar/left/estadisticas/index.htm> Ministerio del Trabajo y Prevision Social - Gobierno de Chile <http://mintrab.gob.cl/>

Ministerio de Trabajo y Seguridad Social - Uruguay <http://www.mtss.gub.uy/marplanilla>

Organización Internacional del Trabajo (OIT) - Chile <http://oitchile.cl/servicio.php>

The Japan Institute for Labour Policy and Training <http://www.jil.go.jp/english/esaikin>

U.S. Department of Labor - United States of America <http:dol.gov/dol/jobs.htm> - Bureau of Labor Statistics <http:dol.gov/dol/jobs.htm> 
Quadro 2. Fontes de Informação para e sobre o Trabalho no Brasil.

Ministério do Planejamento, Orçamento e Gestão/Portal de Serviços e Informações do Governo - Rede Governo <http://www.redegoverno.gov.br/brasilgov/top2.htm>

Ministério do Planejamento, Orçamento e Gestão - Instituto Brasileiro de Geografia e Estatística (IBGE) <http:// www.ibge.gov.br/home/default.php>

Ministério do Trabalho e Emprego <http://www.mte.gov.br/>

Secretaria de Estado de Emprego e Relações do Trabalho (SERT) - São Paulo <http://www.emprego.sp.gov.br>

Secretaria de Economia e Planejamento (SEADE) - Fundação Sistema Estadual de Análise de Dados - São Paulo $<$ http://www.seade.gov.br/>

Senado Federal <http://webthes.senado.gov.br/thes/navthes.shtml>

Universidade Estadual de Campinas/Instituto de Economia - Centro de Estudos Sindicais e de Economia do Trabalho (CESIT) <http://eco.unicamp.br/index.html>

trocar informações com o ambiente externo". A complexidade do universo em estudo, exige um estoque constituído de dados e informações que muitas vezes a instituição disseminadora não consegue suprir. As instituições que se constituem fontes de informação para/sobre o trabalho, selecionadas, além de produzirem os próprios estoques informacionais, também utilizam informações de outras fontes. Esta parceria se dá de diversas formas: por encomenda de pesquisas; programas que realizam em parceria e que geram dados e informações úteis; a utilização de links; formação de redes. Ainda é Davenport (1998, p.270) que orienta quanto a investigação de fontes externas, e esta atividade se constitui num processo composto de quatro etapas: a) identificação das necessidades externas de informação, isto é, os vários tipos de usuários e suas necessidades; b) a decisão de onde procurar a informação; c) a condução da informação externa para dentro da empresa e d) a utilização dessa informação.

No Quadro 3, relacionamos as instituições nacionais pesquisadas e as suas principais fontes de informação.

O levantamento das fontes brasileiras e estrangeiras, seus serviços e produtos informacionais no campo do Trabalho nos permitiu conhecer e ampliar o entendimento de quais são as principais fontes; como elas compõem seus estoques de informação para/sobre o trabalho e comprovar que além das instituições serem suas próprias fontes, isto é produzirem as informações que disponibilizam, outras instituições, já citadas anteriormente, são provedoras deste tipo de informação e ajudam a compor os produtos e serviços oferecidos nos sites da Internet das instituições governamentais.

É interessante notar ainda que as parcerias com as fontes constituídas pelas organizações particulares, como agências de emprego, empresariado, associações de empregados, consultorias de recursos humanos, revistas eletrônicas, enriquecem a dinâmica dos sitesque as utilizam e podem contribuir para torná-los mais completos.

\section{O conteúdo das fontes nacionais e internacionais de informação para/sobre o trabalho}

Para que os estoques de informação para/ sobre o trabalho sejam úteis aos usuários, várias estratégias são utilizadas para que a navegação seja facilitada e os internautas não percam o interesse e tempo procurando a informação que desejam. Percebe-se que alguns sites são elaborados sob um rigoroso planejamento, permitem a interatividade, sofrem controle sobre as informações disponibilizadas e utilizam metodologias para melhor organizar a informação. 
Quadro 3. Instituições nacionais pesquisadas e suas fontes de informação.

Instituição nacionais
Ministério do Planejamento, Orçamento e Gestão/Portal
de Serviços CAT, FGTS, CBO, e Informações do
Governo - Rede Governo

Ministério do Planejamento, Orçamento e Gestão - Instituto Brasileiro de Geografia e Estatística (IBGE)

Ministério do Trabalho e Emprego

Secretaria de Estado de Emprego e Relações do Trabalho (SERT) São Paulo

Fundação SEADE

Secretaria de Economia e Planejamento (SEADE) - Estadual de Análise de Dados - São Paulo

Senado Federal

UNICAMP/ Instituto de Economia - Centro de Estudos Sindicais e de Economia do Trabalho (CESIT)
Fontes de informações externas

Ministério do Trabalho (RAIS, PAT, Seguro Desemprego, CAGED, PIS, SINE, etc.), Ministério da Previdência Social, Ministério da Fazenda, Cadastro Nacional de Entidades Sindicais, Conselho Nacional de Imigração, FUNDACENTRO, PDTE, PAT, BNDES, Fundação Desenvolvimento de Recursos Humanos, DETRAN

Própria

Nada consta

Ministério do Trabalho (RAIS, Seguro Desemprego), Empresariado, DIEESE, Central Digital para o Desenvolvimento - Governo do Estado, PROCON, Prefeituras, Secretaria da Cultura SP, Poupa Tempo, IPT, FAPESP, Secretaria da Educação SP, Defesa Civil do Estado, EMTU/ CDHU/ CETESB/ SARS, Univer-sidades, Secretaria da Fazenda e Secretaria da Agricultura SP, OIT, Ministério da Educação, BNDES, Sindicatos, USP, UNICAMP-CESIT

Prefeituras/CESIT

Fonte própria

Fonte própria/DIEESE
No Anexo 1 está demonstrada as alternativas encontradas na criação de dinâmicas para disponibilização do conteúdo e tornar os portais e sítios mais atraentes, interessantes e úteis.

Apresentadas as dinâmicas e conteúdos dos sites, isto é, como as informações são organizadas no sites para melhor orientação aos usuários/internautas, aprofundamos nossa pesquisa para conhecer o tipo e os detalhes dessa informação que esses conteúdos abarcam.

\section{Quadro das fontes e informações disponibilizadas}

As informações para/sobre o trabalho foram levantadas a partir da observação dos sites das instituições brasileiras e estrangeiras apresentadas. Fizemos um mapa onde foram anotados todos o tipos de informações que se referissem ao tema trabalho o que permitiu classificá-los em oito categorias.

Essa pesquisa pelos serviços de informação disponíveis na Internet nos sites governamentais, aponta que as informações que se referem ao mundo do trabalho pertencem as seguintes categorias gerais: gerais, que o cidadão necessita para mover-se pelo mundo do trabalho e pela vida; aquelas referentes à competência técnica para o trabalho (informações que auxiliam na correta execução do trabalho e sobre o trabalho a ser realizado) num nível pessoal e profissional, que chamaremos de informações para a correta execução de um trabalho e orientações gerais sobre como entender e enfrentar este mundo, que correspondem ao conjunto de informações ao cidadão que estão previstas nos relacionamentos $\mathrm{G} 2 \mathrm{C}$ e C2G. 
Outro grupo é composto por informações relativas ao contexto mais amplo das políticas públicas para o trabalho. As informações para formulação e gerenciamento dessas políticas constantes das estatísticas, relatórios e outras formas de organizá-las e disponibilizá-las é uma exigência muitas vezes de organismos internacionais responsáveis por acompanhá-las. A partir dessa exigência e da pressão dos cidadãos sobre os governos, própria de um ambiente democrático, são disponibilizadas também para a sociedade. Mas o grande usuário é o próprio governo (relacionamento G2G).

As instituições utilizam-se da mesma base tecnológica para divulgar seus serviços ao cidadão, assim, como para troca de informações entre os próprios órgãos do governo, isto é, são parceiros em interface. Além disso, informações administrativas são veiculadas no próprio site.

A Internet é hoje mais uma forma de o governo relacionar-se com o empresariado em geral em termos comerciais e de controle (G2B). São os relacionamentos previstos pela Sociedade da Informação que aos poucos vão sendo implantados e sedimentados.

As informações para/sobre o trabalho disponibilizadas nos sites (detalhes no Apêndice C) das instituições pesquisadas têm correspondência aos grupos de relacionamentos previstos na Sociedade da Informação e referem-se a:

1) Informações gerais para o cidadão trabalhador e sua vida: aquelas úteis às pessoas que procuram emprego pela primeira vez ou que estão se preparando para isso (como se preparar para o trabalho, onde obter informações, órgãos e empresas prestadores de serviços de orientação/preparação/acompanhamento sobre a formação geral para o trabalho, profissões, setores que estão empregando, etc.

2) Informações sobre o portal ou sítio: características de acesso, mapa de sites, sites temáticos que poderão orientar o usuário/ internauta e despertar o interesse pelo aprofun- damento da sua pesquisa e/ou utilização dos sites para as relações com o governo;

3) Legislação: informações que apresentam, explicam, normatizam, as rotinas e procedimentos, direitos deveres (para empregados, empregadores, representações sindicais, de outras representações ligadas ao tema relações de trabalho) e que garantem suas aplicações e controle;

4) Grupos especiais: informações destinadas aos grupos prioritários (empresariado, sindicatos, conselho federal de trabalhadores, convênios, conselho do trabalho, imigração, emigração, trabalho infantil, trabalho indígena, trabalho feminino, entre outros);

5) Formulação e implementação e acompanhamento das políticas públicas: rede de informação, estatísticas locais, setores da economia, pesquisa de indicadores do trabalho, sobre a gestão, plano nacional para registro do trabalho, economia social, relatórios (panorama mercado de trabalho, crescimento de salários, crescimento econômico), planos de investimento, trabalho na indústria pesqueira, guia de referência salarial, atividades realizadas, normativas sobre as políticas de emprego;

6) Divulgação das parcerias, produtos e outros serviços governamentais: campanhas, investigação, convênios, novidades/notícias, publicações, videotecas, novas publicações, outros sites, links gerais, denúncias, feriados, ajuda, sugestões, críticas, aviso de alerta;

7) Informações administrativas: se referem à rotina das próprias organizações governamentais: contratações, licitações, troca de informações entre elas e entre outras;

8) Informações que se referem ao tema trabalho, apresentando uma diversidade de subtemas que não se encaixam nos grupos acima.

A seguir, apresentamos as oito categorias de informações para/sobre o trabalho levantadas e as fontes dessas informações no Brasil (Quadro 4) e no exterior (Anexo 2). 
Quadro 4. Categorias de informação para/sobre o Trabalho (Fontes Nacionais).

\begin{tabular}{|c|c|c|c|c|c|c|c|c|}
\hline Fontes Nacionais & $\begin{array}{l}\text { 1) Gerais } \\
\text { para o } \\
\text { cidadão }\end{array}$ & $\begin{array}{l}\text { 2) Sobre } \\
\text { o site }\end{array}$ & $\begin{array}{l}\text { 3) Legis. } \\
\text { Traba- } \\
\text { Ihistas }\end{array}$ & $\begin{array}{l}\text { 4) Info. } p / \\
\text { Grupos } \\
\text { Especiais }\end{array}$ & $\begin{array}{l}5 \text { ) Polí- } \\
\text { ticas } \\
\text { Públicas }\end{array}$ & $\begin{array}{l}\text { 6) Divul- } \\
\text { gação }\end{array}$ & $\begin{array}{l}\text { 7) Info. } \\
\text { Adminis- } \\
\text { trativas }\end{array}$ & 8) Outros \\
\hline $\begin{array}{l}\text { Centro de Estudos Sindicais } \\
\text { e de Economia do Trabalho }\end{array}$ & & $x$ & & $x$ & $x$ & $x$ & & $x$ \\
\hline $\begin{array}{l}\text { Instituto Brasileiro de } \\
\text { Geografia e Estatística }\end{array}$ & & $x$ & & $x$ & $x$ & $x$ & $x$ & $x$ \\
\hline $\begin{array}{l}\text { Ministério do Trabalho e } \\
\text { Emprego }\end{array}$ & $x$ & $x$ & $x$ & $x$ & $x$ & $x$ & $x$ & $x$ \\
\hline $\begin{array}{l}\text { Portal de Serviços e } \\
\text { Informações do Governo }\end{array}$ & $x$ & $x$ & $x$ & $x$ & $x$ & & $x$ & $x$ \\
\hline $\begin{array}{l}\text { Fundação Sistema Estadual } \\
\text { de Análise de Dados }\end{array}$ & & $x$ & & $x$ & $x$ & $x$ & & $x$ \\
\hline Senado Federal & & $x$ & $x$ & $x$ & & $x$ & & $x$ \\
\hline $\begin{array}{l}\text { Secretaria de Estado de } \\
\text { Emprego e Relações de } \\
\text { Trabalho }\end{array}$ & $x$ & $x$ & $x$ & $x$ & & & & $x$ \\
\hline
\end{tabular}

\section{O N C L U S Ã O}

A pesquisa permitiu, a partir de vários atributos, uma avaliação dos websites das fontes nacionais de informação para/sobre o trabalho quanto aos critérios: informação cadastral, layout, conteúdo, abrangência de propósito, uso, links e restrições percebidas. Esse estudo completo poderá ser acompanhado através da Dissertação de Mestrado disponível, conforme bibliografia.

Percebemos que o estoque de informações existentes nos websites das fontes nacionais é considerável e tem boa qualidade. Porém, para que o acesso seja democratizado e levado a um maior número de pessoas, pontos levantados como importantes pela Sociedade da Informação ainda estão por atingir suas metas. Falta ampliação das bases tecnológicas e melhor gerenciamento dos processos internos do governo para atender às diferentes demandas. $A$ Internet é uma grande mídia e poderá tornar-se um instrumento efetivo, contribuindo para a construção da cidadania e da democratização das oportunidades ocupacionais.

Por parte dos governos é importante que haja um esforço para ampliar os serviços nessa área informacional, incrementar o que já existe, integrando as diversas instituições e mídias para que de fato haja universalização do acesso à informação. À Internet deverão ser somados, de forma planejada, a radiodifusão, os serviços dos correios dos meios impressos e programas educacionais. Não basta organizar, disponibilizar a informação para/sobre o trabalho, é preciso divulgar/disseminar. Não se notam também ações coordenadas entre os governos federais, estaduais e municipais. Há muitas possibilidades de interfaces que não são aproveitadas. Não existe, na prática, a noção de rede para este setor informacional. As informações são estanques, o que obriga o usuário a ter um conhecimento prévio dos meandros da burocracia governamental para melhor recuperar a informação que procura. O usuário nem sempre é levado ou incentivado a continuar sua busca, a menos que conheça esta burocracia. Conclui-se que não há compartilhamento de informações nas diversas esferas governamentais (referente ao relacionamento $\mathrm{G} 2 \mathrm{G}$ - Government to Government, previsto pela Sociedade da Informação).

Já o controle das obrigações sociais ligadas a área do trabalho (tributação) sobre o 
empresariado está melhor sistematizado (relacionamento G2B - Government to Business). É importante conhecer a demanda dos cidadãos que são diferentes em instrução, nível de renda, possibilidade de acesso aos meios de comunicação, cultura, hábitos e necessidades. Além disso, implementar campanhas e programas educativos que utilizem e/ou incentivem o uso do riquíssimo estoque de informações governamentais disponível no campo do trabalho (relacionamento G2C - Government to Citizen).

\section{REFERÊ NCIAS}

BARRETO, A.A. Os destinos da informação: entre o cristal e a chama. Informação e Sociedade: Estudos, João Pessoa, v.9, n.2, p.371-382, 1999a.

BARRETO, A.A. A oferta e a demanda da informação: condições técnicas, econômicas e políticas. Ciência da Informação, Brasília, v.28, n.2, 1999b. Disponível em: <http://www.ibct.com>. Acesso em: 9 jan. 2005.

BARRETO, A.A. Políticas Nacionais de Informação. Palestra Proferida CINFOR 2004, Salvador. Disponível em: <http:www.alternex.com>. Acesso em: 17 jan. 2005.

CAMPELO, B.S.; CAMPOS, C.M. Fontes de informações especializadas: características e utilização. 2.ed. Belo Horizonte: UFMG, 1993.

DAVENPORT, T.H.; PRUSAK, L. Ecologia da Informação. São Paulo: Futura, 1998.

DIAS, C.A. Hipertexto: evolução histórica e efeitos sociais. Revista Ciência da Informação, v. 28, n.3, 1999.

FERREIRA, R.S.A sociedade da informação no Brasil: um ensaio sobre desafios do Estado. Ciência da Informação, v.32 n.1, Brasília, 2003.
Disponível em: <http://www.scielo.br>. Acesso em: 17 jan. 2005.

LARA, M.L.G. Diferenças conceituais sobre termos e definições e implicações na organização da linguagem documentária. Ciência da Informação, Brasília, v.33, n.2, p.91-96, 2004.

LÉVY, P. As tecnologias da inteligência. Rio de Janeiro: Ed. 34. 2000.

McGee, G.; PRUSAK, L. Gerenciamento estratégico da comunicação. 7.ed. Rio de Janeiro: Campos, 1994.

MIOTTO, L.B. Comunicação e espaço público na sociedade da informação: reflexões sobre a política contemporânea. In: OLIVEIRA, M.J.C. Comunicação pública. Campinas: Alínea, 2004.

MOURA, L. Como escrever na rede - manual de conteúdo e redação para Internet. Rio de Janeiro: Record, 2002.

O'BRIEN, J.A. Sistemas de informação e as decisões gerenciais na era da Internet. 9.ed. São Paulo: Saraiva, 2003.

TAKAHASHI, T. (Org.). Sociedade da Informação no Brasil: Livro Verde. Brasília: Ministério da Ciência e Tecnologia, 2000. p.31-77. 


\section{ANEXO 1}

Dinâmica de conteúdo

Instituições
Ministério do Planejamento, Orçamento e Ges-
tão/Portal de Serviços e Informações - Rede
Governo

Ministério do Planejamento, Orçamento e Gestão/Censos - Geociências - Instituto Brasileiro de Geografia e Estatística

Ministério do Trabalho e Emprego (MTE)

Secretaria de Estado de Emprego e Relações do Trabalho (SERT) - São Paulo

Secretaria de Economia e Planejamento/SEADE - Sítios - Mapa do Fundação Sistema Estadual de Análise de Dados S. Paulo

\section{Senado Federa}

Universidade Estadual de Campinas/Instituto de Economia - Centro de Estudos Sindicais e de Economia do Trabalho (CESIT)
Dinâmica do Conteúdo

Serviços e Informações (Emprego e Trabalho e Oportunidade de Trabalho - Passo a Passo (Crianças e Adolescentes) - Evite Vilas - Abra seu negócio - Dicas do Governo Eletrônico - Bancos - Pessoas Portadoras de Deficiência - Apoio a Empresas - Pesquisas Escolares - Oportunidades de Trabalho, Alvarás - Aposentado e Pensionista - Auxílios - Certidões Negativas - Denúncias - Documentos - Legislação e Normas - Processos - E-gov - Fale com - Instale Rede Gov - Mapa do Portal - Fale Conosco - Downloads - Links

Indicadores Conjunturais - Economia - Canais - População - Canais - Calendário de Eventos - A instituição - Home - Fale conosco - Locais de Atendimento - Estatísticas do site - Editais e Licitações - Downloads - Pesquisas - Estimativas - Catálogo IBGE (Arquivos digitais, Cartas, Mapas e Cartogramas, Publicações) Biblioteca (Acervos, Atendimento) - Periódicos - Pesquisa On line) - Prestação de contas - Produtos - Venda

Trabalhador - Empregador - Jovem Trabalhador - Entidades - Brasil Gov - Portal de Serviços - Trabalho no MTE - Identificação - Cadastra-se - PortalCBO - Metas e Execução da Qualificação - Profissional - Habilitação Seguro Desemprego - Tire suas Dúvidas - Consultas - Serviços - Busca Geral - Ministério - Mercado de TrabaIho - Economia Solidária - Inspeção do Trabalho - Portal de Serviços - Ouvidoria - Dúvidas/Fale Conosco - Mapa de Navegação - Estatísticas - Observatório do Mercado de Trabalho - Escolha o tema ou programa de Interesse - Outros serviços e informações - O que é o SINE - Menu - Informações - Intermediação de Mão de Obra/ IMO - Estatísticas - Legislação - Consulta aos Postos do SINE - Alô Trabalho/ Central de Atendimento ao Trabalhador - Delegacias do Trabalho - Informativo-Conselho Sindical - Convocações para Audiências - Desempenho - Dados Sócio Econômicos.

SP Notícias - Ações do Governo - Invista em São Paulo - Juventude - Serviços Online - Linha Direta - Perfil - Home - Serviços - Programas - Balcão de Empregos - Notícias - Conheça a SERT - Sert \& Você - Serviços Públicos - Enquête/Opine - Visitantes - Páginas Visitadas - Sites Interessantes - Área exclusiva para alunos/Aula Virtual - Entidades Conveniadas pela SERT para Qualificação Profissional - Relatórios - Ações da SERT- Downloads - Candidato - Empresa - Ajuda - Mapa do site - Contato - Pesquisa - Fale Conosco - Biblioteca - Links - Agenda - Áreas Temáticas - Última atualização.

Institucional - Atendimento - Ouvidoria - Calendário - Outros sítio - Fale Conosco - Produtos por tema - Lista completa de produtos (alfabética/temas) - Publicações Eletrônicas - Projetos e parcerias - Livraria Publishop - Estimativa diária da população de São Paulo

Bibliotecas - Thesauros

Publicações - Artigos - Teses - Monografias - Docentes - Associações e Entidades - Links - Contato - Como chegar - Cursos - Pesquisa - Biblioteca - Eventos - Equipe - Cadernos - Livros - Contatos - Venda de Publicações 


\section{Anexo 2}

Categorias de informação para/sobre o Trabalho (Fontes Nacionais).

\begin{tabular}{|c|c|c|c|c|c|c|c|c|}
\hline Instituições & $\begin{array}{l}\text { 1) Gerais } \\
\text { para o } \\
\text { cidadão }\end{array}$ & $\begin{array}{l}\text { 2) Sobre } \\
\text { o site }\end{array}$ & $\begin{array}{l}\text { 3) Legis. } \\
\text { Traba- } \\
\text { Ihistas }\end{array}$ & $\begin{array}{l}\text { 4) Info. } p / \\
\text { Grupos } \\
\text { Especiais }\end{array}$ & $\begin{array}{l}\text { 5) Polí- } \\
\text { ticas } \\
\text { Públicas }\end{array}$ & $\begin{array}{l}\text { 6) Divul- } \\
\text { gação }\end{array}$ & $\begin{array}{l}\text { 7) Info. } \\
\text { Adminis- } \\
\text { trativas }\end{array}$ & 8) Outros \\
\hline $\begin{array}{l}\text { Agência Europea para la } \\
\text { Leguridad y la Salud en el } \\
\text { Trabajo }\end{array}$ & $x$ & $x$ & $x$ & $x$ & $x$ & $x$ & & $x$ \\
\hline $\begin{array}{l}\text { Alaska Dept. of Labour \& } \\
\text { Workforce Development }\end{array}$ & $x$ & $x$ & $x$ & $x$ & $x$ & $x$ & & $x$ \\
\hline $\begin{array}{l}\text { Australian Gov.- Australian } \\
\text { Workplace }\end{array}$ & $x$ & $x$ & $x$ & $x$ & $x$ & $x$ & & $x$ \\
\hline $\begin{array}{l}\text { Bolsa de Trabajo - Guia de } \\
\text { Sitios Spain }\end{array}$ & $x$ & $x$ & $x$ & $x$ & $x$ & $x$ & & $x$ \\
\hline $\begin{array}{l}\text { Department of Labour - New } \\
\text { Zealand }\end{array}$ & $x$ & $x$ & $x$ & $x$ & $x$ & $x$ & & $x$ \\
\hline $\begin{array}{l}\text { Divisão Geral de Estudos, } \\
\text { Estatística e Planejamento - } \\
\text { Portugal }\end{array}$ & $x$ & $x$ & $x$ & $x$ & $\mathrm{x}$ & $x$ & $x$ & $x$ \\
\hline $\begin{array}{l}\text { Portal Europeu da Mob. Pro- } \\
\text { fissional }\end{array}$ & $x$ & $x$ & $x$ & $\mathrm{x}$ & $x$ & $x$ & $x$ & $x$ \\
\hline $\begin{array}{l}\text { European Statistical } \\
\text { System }\end{array}$ & $\mathrm{x}$ & $x$ & $x$ & $x$ & $x$ & $x$ & $x$ & $x$ \\
\hline $\begin{array}{l}\text { Government du Canada - } \\
\text { Human }\end{array}$ & $x$ & $x$ & $x$ & $x$ & $x$ & $x$ & $x$ & $x$ \\
\hline $\begin{array}{l}\text { Resources and Skills } \\
\text { Development }\end{array}$ & $x$ & $x$ & $x$ & $x$ & $x$ & $x$ & $x$ & $x$ \\
\hline $\begin{array}{l}\text { International Labour } \\
\text { Organization }\end{array}$ & $x$ & $x$ & $x$ & $x$ & $x$ & $x$ & $x$ & $x$ \\
\hline $\begin{array}{l}\text { Ministère de L'Employ, du } \\
\text { Travail e de la Cohesion } \\
\text { Sociale - France }\end{array}$ & $x$ & $x$ & $x$ & $x$ & $x$ & $x$ & $x$ & $x$ \\
\hline $\begin{array}{l}\text { Ministero del Lavoro e } \\
\text { delle Politiche Sociali - } \\
\text { Itália }\end{array}$ & $x$ & $x$ & $x$ & $x$ & $x$ & $x$ & $x$ & $x$ \\
\hline $\begin{array}{l}\text { Ministerio das Actividades } \\
\text { Econ. e do Trabalho - Por- } \\
\text { tugal }\end{array}$ & $x$ & $x$ & $x$ & $x$ & $x$ & $x$ & $x$ & $x$ \\
\hline $\begin{array}{l}\text { Ministerio de Trabajo } \\
\text { Seguridad Social - Argen- } \\
\text { tina }\end{array}$ & $x$ & $x$ & $x$ & $x$ & $x$ & $x$ & $x$ & $x$ \\
\hline $\begin{array}{l}\text { Ministerio del Trabajo y } \\
\text { Prevision Social - Chile }\end{array}$ & $x$ & $x$ & $x$ & $x$ & $x$ & $x$ & $x$ & $x$ \\
\hline $\begin{array}{l}\text { Ministerio de Trabajo y } \\
\text { Seguridad Social - } \\
\text { Uruguay }\end{array}$ & $x$ & $x$ & $x$ & $x$ & $x$ & $x$ & $x$ & $x$ \\
\hline $\begin{array}{l}\text { Oganización Intern. } \\
\text { Trabajo Chile }\end{array}$ & $x$ & $x$ & $x$ & $x$ & $x$ & $x$ & $x$ & $x$ \\
\hline $\begin{array}{l}\text { The Japan Institute for } \\
\text { Labour Policy and } \\
\text { Training }\end{array}$ & $x$ & $x$ & $x$ & $x$ & $x$ & $x$ & $x$ & $x$ \\
\hline $\begin{array}{l}\text { U.S.Department of Labour - } \\
\text { Bureau of Labor Statistics }\end{array}$ & $x$ & $x$ & $x$ & $x$ & $x$ & $x$ & $x$ & \\
\hline
\end{tabular}

